\title{
Looking Beyond FDA Warning Letters to Explore Unforeseen Trouble Spots in eDTCA: A Response to Recent Commentaries
}

\author{
Hyosun Kim*
}

\author{
*Correspondence to: Hyosun Kim, Email: Hyosun.Kim@uwsp.edu \\ Copyright: ( 2016 by Kerman University of Medical Sciences \\ Citation: Kim H. Looking beyond FDA warning letters to explore unforeseen \\ trouble spots in eDTCA: a response to recent commentaries. Int J Health Policy \\ Manag. 2016;5(10):611-612. doi:10.15171/ijhpm.2016.92 \\ Received: 20 June 2016; Accepted: 2 July 2016; ePublished: 10 July 2016
}

$\mathrm{I}$ would like to take this opportunity to express my deepest gratitude to everyone who responded to my study entitled: "Trouble Spots in Online Direct-to-Consumer Prescription Drug Promotion: A Content Analysis of FDA Warning Letters." Scholars from several different fields, including medical science, pharmacy, business, and communication have all participated in the discussion of current issues and the future of direct-to-consumer advertising (DTCA), bringing multifaceted viewpoints to bear on prescription drug marketing based on their own disciplines. It was a high honor and a truly gratifying experience to receive such valuable comments from colleagues in my own field, as well as scholars who have dedicated their research in DTCA of prescription drugs in other fields. I appreciate their insights into the research on online DTCA of prescription drugs, which enabled me to broaden my perspective on an area of prescription drug promotions that could not only influence consumers, but also other stakeholders, such as policymakers, clinicians, and marketers. These commentaries expand on ideas of current regulatory issues regarding online promotions, and discuss further unforeseen concerns that might arise due to emerging media options consumers will have in the future-all of which warrant more research and close scholarly attention.

With the advent of new technologies and the variety of communication platforms available online, pharmaceutical marketers' promotional tactics for prescription drugs have posed a lot of questions. ${ }^{1}$ DTCA is only permitted in the United States and New Zealand; however, Tim Mackey, Barbara Mintzes, Brian Southwell, and Douglas Rupert suggest further regulatory inquiries regarding the global reach of prescription drug DTCA,,$^{2-4}$ as the Internet has made it possible to reach people all around the world. Pharmaceutical manufacturers' social media accounts and brand-specific websites are accessible to US and non-US consumers alike; although these online promotional venues indicate that they are intended only for US residents, pharmaceutical manufacturers rarely block non-US access. ${ }^{3,5}$ Virtually all English-speaking countries and English-speaking individuals can access prescription drug information from non-US markets. Canadian policymakers haves already been struggling with DTC broadcasting ads transmitted from the United States, and Health Canada maintains a watchdog function to block eDTCA content. ${ }^{2,6}$ Online promotional content of prescription drugs can clearly cross international borders and has the potential to run faster and much farther away as technology advances. As such, eDTCA originating in the United States can result in unbidden consequences to consumers, policy-makers, and pharmaceutical practitioners outside the borders of the United States, where DTCA is not legal, as Mackey, Mintzes, Southwell and Rupert pointed out quite well.

Based on key findings from my study, all the commentaries argue that off-labeling is the most serious problem resulting from eDTCA of prescription drugs, followed by the lack of substantial information associated with drug use. In addition, Southwell and Rupert suggest that such an issue becomes more serious on the mobile environment because mobile space is much more limited than that of the computer, and many online websites are still not mobile-friendly in their design, which raises questions as to how such broken and incomplete drug information available on mobile websites influences viewers. ${ }^{4}$ Also, a surprising finding from my study was that only 2 alleged violations were reported with regard to social media within the recent 10 year span, given the growing use and popularity of social media as a health informationseeking channel.,7 Issac Wanasika, therefore, strongly argues that drug manufacturers' promotional activities on social media warrant closer scrutiny by the Food and Drug Administration (FDA). ${ }^{7}$

Francesca Renee Dillman Carpentier specifically examined promotional activities of prescription drugs on social media, suggesting that, in many cases, social media content coupled with message source factor blurs the line between marketcontrolled vs. market-influenced promotions. ${ }^{8}$ The nature of social media allows people to create messages, as well as simply share their own content or posts that someone else has already created. As such, it is often difficult to identify the source of the content; also, shared content, in the form of "retweeting" or "liking," obscures where the content originated, which challenges whether the company or the consumers are responsible for the content. ${ }^{8}$ According to Southwell and Rupert, consumers are actively discussing their own experiences with prescription drugs with other fellow consumers-ie, patients or caregivers-on social media. ${ }^{4}$ They actively engage in conversations and share information with 
like-minded people who have similar experiences. Dillman Carpentier also suggests, however, that there is no way to oversee branded user-generated content distributed outside of pharmaceutical companies' control, which can affect public health. ${ }^{8}$ Thus, social media is much more complex and different from other types of online platforms, and therefore, requires close attention by policy-makers.

Another area that plays a significant role in eDTCA is help-seeking ads., ${ }^{3,9}$ Barbara Minzes argues that the helpseeking type of ads-also referred to as disease-specific or disease awareness ads-can be problematic in the online environment because a "clicking" of the ads takes users to branded websites landing pages, which brings us back the "fair balance" dilemma. ${ }^{3}$ Based on a series of studies exploring disease-specific ads, Brent Rollins suggests, in terms of the disease prevention viewpoint, that disease-specific ads can be effective, as they encourage patients to discuss their symptoms with doctors and to seek health information. ${ }^{9}$ Disease-specific ads can be useful, but it is noteworthy that these ads are not free from the "fair balance" issue in online promotions.

Drawing on the original study, these commentaries expanded the issues regarding DTCA and shed light on possible violations that do need careful scrutiny by policy-makers, including the FDA. The FDA's warning letters have been studied by many scholars ${ }^{10,11}$; however, these letters may not be a sufficient data source for determining all the trouble spots concerning DTCA., ${ }^{2,3}$ Future research, thus, needs to look at DTCA from multiple angles, which indicates that an interdisciplinary approach would help in understanding the issues surrounding DTCA. I appreciate commenters who brought their expertise from their own fields in this regard. We study DTCA not merely to ban the ads or to force the FDA to issue more aggressive warning letters to pharmaceutical companies, but to provide trustful and helpful health information to consumers so they can make informed decisions. Admittedly, without comprehensive guidelines, pharmaceutical makers' promotional tactics have been adept at crafting information online ${ }^{12}$ with, for example, paid celebrity endorsements ${ }^{8}$ and native advertising content. ${ }^{13}$ It is important to consider, however, that patients and caregivers are vulnerable populations who may be at life-threatening risk or will likely be grasping at straws to survive. ${ }^{1,2,7}$ Therefore, our contribution in academia should be helping policymakers to establish comprehensive guidelines so that industry can communicate both safely and effectively with consumers.

Ethical issues

Not applicable.

\section{Competing interests}

Author declares that she has no competing interests.

Author's contribution

$\mathrm{HK}$ is the single author of the paper.
References

1. Kim H. Trouble spots in online direct-to-consumer prescription drug promotion: a content analysis of FDA warning letters. Int J Health Policy Manag. 2015;4(12):813-821. doi:10.15171/ ijhpm.2015.157

2. Mackey TK. Digital direct-to-consumer advertising: a perfect storm of rapid evolution and stagnant regulation: Comment on "Trouble spots in online direct-to-consumer prescription drug promotion: a content analysis of FDA warning letters." Int $J$ Health Policy Manag. 2016;5(4):2271-2274. doi:10.15171/ ijhpm.2016.11

3. Mintzes B. The tip of the iceberg of misleading online advertising: Comment on "Trouble spots in online direct-toconsumer prescription drug promotion: a content analysis of FDA warning letters." Int J Health Policy Manag. 2016;5(5):329331. doi:10.15171/ijhpm.2016.19

4. Southwell, Brian G. RDJ. Future challenges and opportunities in online prescription drug promotion research: Comment on "Trouble spots in online direct-to-consumer prescription drug promotion: a content analysis of FDA warning letters." Int J Health Policy Manag. 2016;5(3):211-213. doi:10.15171/ijhpm.2016.05

5. Liang BA, Mackey T. Direct-to-consumer advertising with interactive internet media: global regulation and public health issues. J Am Med Assoc. 2011;305(8):824-825. doi:10.1001/ jama.2011.203

6. Gibson S. Regulating direct-to-consumer advertising of prescription drugs in the digital age. Laws. 2014;3(3):410-438.

7. Wanasika I. the conundrum of online prescription drug promotion: Comment on "Trouble spots in online direct-toconsumer prescription drug promotion: a content analysis of FDA warning letters." Int J Health Policy Manag. 2016;5(6):391392. doi:10.15171/ijhpm.2016.33

8. Dillman Carpentier FR. Considering the future of pharmaceutical promotions in social media: Comment on "Trouble spots in online direct-to-consumer prescription drug promotion: a content analysis of FDA warning letters." Int $J$ Health Policy Manag. 2016;5(4):283-285. doi:10.15171/ijhpm.2016.15

9. Rollins BL. Still the Great Debate - "Fair balance" in direct-toconsumer prescription drug advertising: Comment on "Trouble spots in online direct-to-consumer prescription drug promotion: a content analysis of FDA warning letters." Int $J$ Health Policy Manag. 2016;5(4):287-288. doi:10.15171/ijhpm.2016.17

10. Sheehan K. Balancing acts: an analysis of Food and Drug Administration letters about direct-to-consumer advertising violations. J Public Policy Mark. 2003;22(2):159-169.

11. Hoy MG, Park JS. Principles in action: an examination of Food and Drug Administration letters involving violative internet promotions from 1997 to 2012. J Public Policy Mark. 2014;33(2):127-142. doi:10.1509/jppm.12.097

12. Doran $\mathrm{E}$. Trouble spots in online direct-to-consumer prescription drug promotion: teaching drug marketers how to inform better or spin better? Comment on "Trouble spots in online direct-toconsumer prescription drug promotion: a content analysis of Fda warning letters. Int J Health Policy Manag. 2016;5(5):333-335. doi:10.15171/ijhpm.2016.20

13. gparisi. FTC to Pharma on Native Advertising: Proceed with Caution. Coalitation for Healthcare Communication website. http://www.cohealthcom.org/2016/04/18/ftc-to-pharma-onnative-advertising-proceed-with-caution/. Accessed June 23, 2016. Published July 1, 2016. 